Research Article

\title{
Experimental Study on Cumulative Plastic Deformation of Coarse-Grained Soil High-Grade Roadbed under Long-Term Vehicle Load
}

\author{
Zhongming He $\left({ }^{1},{ }^{1}\right.$ Yaxin Liu, ${ }^{1}$ Haolong Tang, ${ }^{1}$ Yihang Xing, ${ }^{1}$ and Hanbing Bian ${ }^{2}$ \\ ${ }^{1}$ School of Traffic and Transportation Engineering, Changsha University of Science \& Technology, Changsha 410114, China \\ ${ }^{2}$ Laboratory for the Study of Microstructures and Materials Mechanics, University of Lorraine, Metz 57070, Lorraine, France \\ Correspondence should be addressed to Zhongming He; hezhongming45@126.com
}

Received 26 March 2018; Accepted 16 September 2018; Published 4 November 2018

Guest Editor: Rihong Cao

Copyright ( $\odot 2018$ Zhongming He et al. This is an open access article distributed under the Creative Commons Attribution License, which permits unrestricted use, distribution, and reproduction in any medium, provided the original work is properly cited.

\begin{abstract}
According to the change characteristics of the subgrade moisture content and the mechanical calculation of several typical highways, the test scheme of the permanent deformation of coarse soil was formulated. The relationship between the permanent deformation of coarse-grained soil and the stress level, compaction degree, moisture content, and loading frequency was studied by cyclic loading triaxle testing. The results show that the permanent deformation of coarse-grained soil increases with the increase in partial stress and moisture content and decreases with the increase in compaction degree. The experimental data were fitted by the Tseng-Lytton model, and the correlation coefficients were $92 \%$, which indicated that the model could be used to predict the permanent deformation of coarse soil. The relationships between the model coefficient and the moisture content and spring back modulus were obtained by the multiple regression method. Finally, the permanent deformation of the subgrade soil was calculated by using the layered summation method and a typical subgrade pavement structure.
\end{abstract}

\section{Introduction}

At present, research on the impact of vehicle loads on roads in China and abroad has focused on the road surface and not the roadbed, which is problematic [1-3]. When the American Highway Association of the State Highways (AASHO) conducted an experimental study of road ruts, it was found that $9 \%$ of road surface ruts were caused by roadbeds [4]. However, because of the unique traffic conditions of domestic expressways, the subgrade soil is affected by long-term vehicle heavy load, which will also cause greater plastic deformation and accelerate the production of road ruts. Elliot and Thompson believed that the permanent deformation of subgrade soil had a significant impact on the performance of asphalt pavement, and they also believed that road designers were less concerned with the deformation of subgrade [5]. To date, few scholars have studied the impact of vehicle loads on the deformation of subgrade. The reasons are as follows. The permanent deformation test of subgrade soil is expensive, cumbersome, and time- consuming, and researchers usually use resilient subgrade soil as the subgrade design. Indicators ignore the permanent deformation of subgrade soil. Pavement can be reduced by plastic materials and gradation, and the deformation of roadbeds becomes one of the most important factors in the production of road ruts.

Lin et al. studied the three-dimensional effect of tensile strength in a standard Brazilian test considering contact length [6]. Wang et al. studied the relationship between UCS ratings and the surface hardness of Schmidt hammers [7]. Wang et al. conducted indoor research on the strength characteristics of expansive soil treated with jute fiberreinforced material [8]. Coarse-grained soil is a soil-rock mixture with a particle size of more than $50 \%$ of the total mass in the particle size range of $d=0.075$ to $60 \mathrm{~mm}$ due to its high porosity, high water permeability, high shear strength, high bearing capacity, and good compactness. Such excellent engineering characteristics have been widely used in the construction of high embankments for highways in southern China. However, the impact of vehicle load on 
a coarse-grained soil embankment has rarely been studied. This paper intends to analyze the stress status of the typical expressway subgrade in China and formulate a reasonable test program to study the load deformation characteristics of coarse-grained soil subgrade under different stress levels, confining pressures, loading times, compaction degrees, and moisture contents. The research results can provide a theoretical basis for the remediation of road damages and provide corresponding guidance for traffic management.

\section{Experimental Design}

2.1. Experimental Soil Samples. The soil samples were taken from a highway $\mathrm{K} 56+300-\mathrm{K} 56+350$, and the soil samples were made of soil, sand, and gravel. According to the "Geotechnical Test Code" (JTG E40-2007) of the coarsegrading soil classification criteria, the original soil sample was described as coarse-grained soil. Due to the limitations of the test conditions, the maximum particle size of the coarse particles in the coarse-grained soil samples should be less than $20 \mathrm{~mm}$. The coarse particle size of the site was large, so the indoor experiment needed to be limited to soil sample sizes that were acceptable for the test instruments; additionally, to ensure the greatest degree of engineering properties of the soil, the relationship of the original soil samples and the test soil was assessed. Guo, in a study of the characteristics of coarse-grained soil, proposed the maximum particle size exclusion method, equivalent replacement method, and parallel grading method for soil preparation [9]. Chen et al. prepared a red sandstone coarse-grained soil sample with the parallel grading method [10]. Liu used the maximum particle size exclusion method to prepare a gravel soil triaxial test sample [11]. The author referred to their research results, using the maximum particle size exclusion method to prepare a coarse-grained soil triaxle sample, and the sample particles with sizes greater than $20 \mathrm{~mm}$ were removed directly during the preparation of the samples; the sample products are shown in Figure 1. The physical and mechanical parameters of the test soil were obtained through the screening test, the compaction test, the rebound modulus test, and the direct shear test on the soil sample. The parameters of the test soil are shown in Tables 1 and 2 .

2.2. Cyclic Loading Test Program. The R-8001T large-scale dynamic triaxial test system of the National Engineering Laboratory of Highway Engineering Maintenance Technology was used to carry out the cyclic loading test on subgrade soil. Consistent with the characteristics of the instrument, the specimen was cylindrical with a diameter of $100 \mathrm{~mm}$ and a height of $200 \mathrm{~mm}$.

2.2.1. Moisture Content. The best moisture content of the test soil measured by a compaction test was $6.8 \%$. According to the Elliott survey, the subgrade moisture content was 1 to 1.2 times the best moisture content after subgrade completion [5]. The frequent rains were taken into account in the southern rainy season, and part of the rainwater infiltrated into the subgrade soil through the embankment slope and pavement cracks, resulting in an increase in moisture content of some subgrade soils. Therefore, the soil samples had water cuts of $6.8 \%, 8.1 \%$, and $9.5 \%$, representing the best moisture content of the soil samples, the water content during the subgrade operation period, and the moisture content of the subgrade soil (pavement cracks) during the rainy season rainfall infiltration, respectively.

2.2.2. Compactness. China's “Code for the Design of Highway Subgrade" (JTG D30-2015) stipulates that the subgrade compaction degree should not be less than $96 \%$ within a depth of $0.8 \mathrm{~m}$ below the bottom surface of the pavement of expressways and highway roads; for the depth below the road surface from $0.8 \mathrm{~m}$ to $1.5 \mathrm{~m}$, the subgrade compaction should not be less than $94 \%$. To increase the comparability of compaction, two compaction levels of $96 \%$ and $91 \%$ were used in this test.

2.2.3. Loading Conditions. Pumphrey and Lentz carried out a repeated loading test on Florida sand and found that when the stress ratio is less than 0.75 , different confining pressures have little effect on the permanent deformation [12]. Zhang et al. believed that the compressive stress of the roadbed in China's operation period was approximately $28 \mathrm{kPa}$. Therefore, the confining pressure of this test was $28 \mathrm{kPa}$ [13].

2.2.4. Deviatoric Stress. According to numerical simulation and field testing, Zhang determined that the vehicle load on the top surface of expressway subgrade is approximately $30 \sim 60 \mathrm{kPa}$, and the vehicle load waveform on the top of the subgrade could be approximated as a half-sine pulse waveform [14]. Therefore, the dynamic stress level was considered to be $30 \mathrm{kPa}, 45 \mathrm{kPa}$ and, $60 \mathrm{kPa}$. The load waveform was a half-sine pulse load, the load frequency was $1 \mathrm{~Hz}$, and the load time was $0.2 \mathrm{~s}$.

2.2.5. The Number of Loads. To simulate the long-term effect of vehicle load on subgrade soil, the number of cyclic loads should be similar to the actual situation. For expressways, the standard axle load of vehicles reached $10^{7}$ during the road design period. However, due to experimental limitations, it was not possible to simulate millions of vehicle loads. Therefore, more than 10,000 loading times were generally used to reflect the long-term effect of traffic load (Table 3).

\section{Cyclic Loading Test Results}

3.1. Effect of Dynamic Stress on Plastic Deformation. Analysis of the effect of dynamic stress level on the plastic deformation was carried out with the same soil sample conditions and different partial stresses. Three conditions-A1, A2, and A3-with a moisture content of $6.8 \%$ and three conditions-C1, C2, and $\mathrm{C} 3$ - with a water content of $9.5 \%$ were analyzed. The cumulative plastic strain curves of the six working conditions are shown in Figures 2 and 3. 


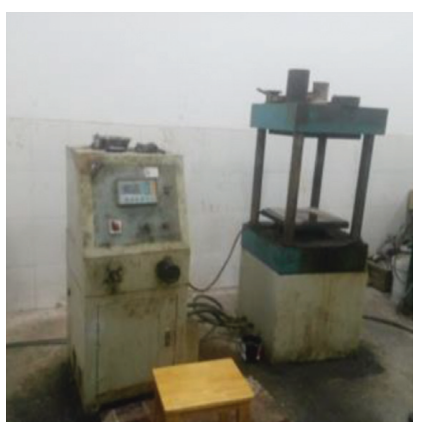

(a)

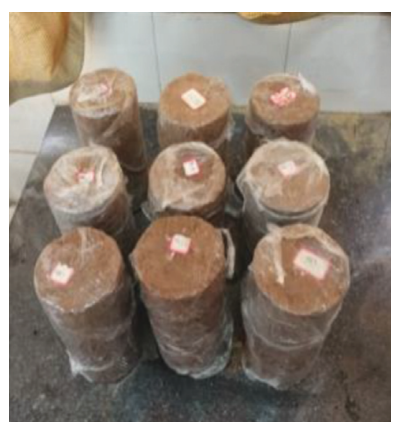

(b)

FIGURE 1: Fabrication of the triaxial specimens.

TABLE 1: Coarse-grained soil particle grading.

\begin{tabular}{lcccccccc}
\hline Particle size $(\mathrm{mm})$ & 20 & 10 & 5 & 2 & 1 & 0.5 & 0.25 & 0.075 \\
\hline Content $(\%)$ & 100 & 89.5 & 79.3 & 60.4 & 32.2 & 20.4 & 15.1 & 13.4 \\
\hline
\end{tabular}

TABLE 2: Coarse-grained soil basic physical dynamics reference number.

\begin{tabular}{lcccc}
\hline Maximum dry density $\left(\mathrm{g} / \mathrm{cm}^{3}\right)$ & The best moisture content $(\%)$ & Modulus of resilience $(\mathrm{MPa})$ & Cohesion $(\mathrm{kPa})$ & Internal friction angle $\left({ }^{\circ}\right)$ \\
\hline 2.21 & 6.8 & 100 & 25 & 32 \\
\hline
\end{tabular}

TABle 3: Permanent deformation test scheme.

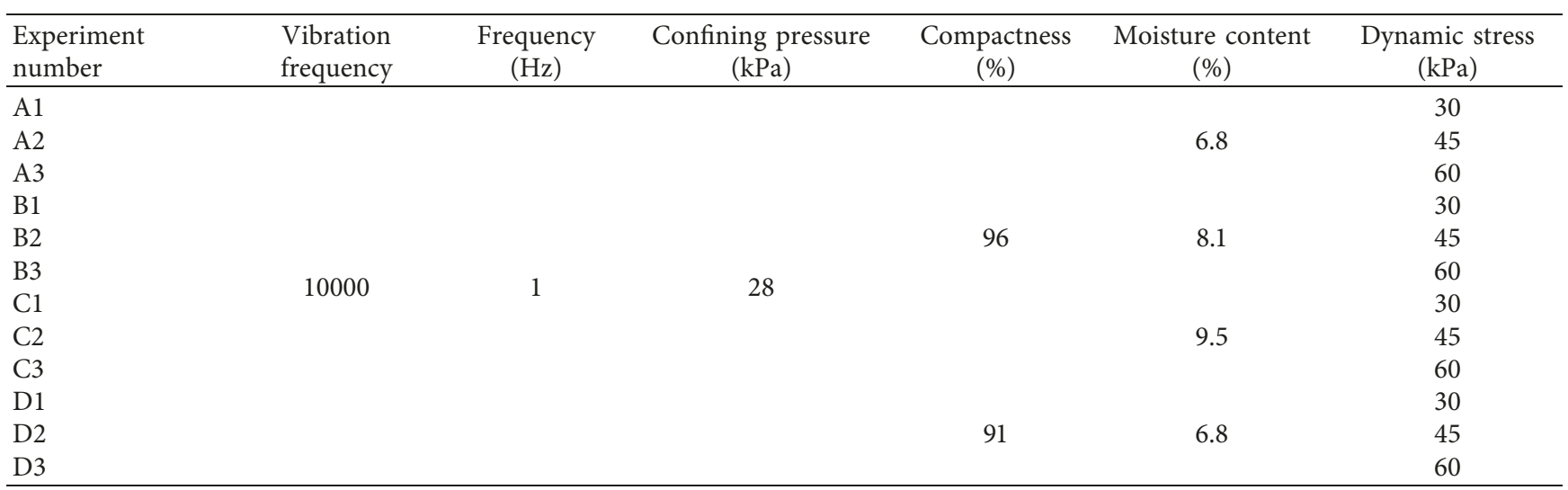

As shown in Figures 2 and 3, the permanent deformation curve under different dynamic stress conformed to the basic law of gradual increase. When the dynamic stress was within a certain range, with the increase in cyclic loading times, the axial cumulative deformation of the soil increased, and the axial cumulative plastic strain rate decreased continuously, which caused the axial deformation to approach a limit value. For the preloading, the axial deformation rate was faster, and the accumulated deformation of the first 2000 loading cycles accounted for approximately $80 \%$ of the total deformation. As shown in Figure 1, the moisture content was $9.8 \%$ when the partial stress was $30 \mathrm{kPa}$, and the plastic strain was $0.07 \%$ after 10,000 cycles of cyclic loading. The specimen was smaller under these conditions. When the partial stress was $45 \mathrm{kPa}$ and $60 \mathrm{kPa}$, the plastic strain of the specimen was $0.1 \%$ and $0.15 \%$, respectively. The experimental results showed that as the dynamic stress increased, the permanent deformation value increased, and the plastic deformation of the coarsegrained soil was affected by the dynamic stress amplitude.

3.2. Effect of Moisture Content on Plastic Deformation. To accurately show the effect of moisture content on plastic deformation, the plastic deformation of the soil samples with different moisture contents under the same compaction degree and partial stress were compared. Figure 4 shows the plastic deformation curve of the soil samples with different moisture contents (A1, B1, and $\mathrm{C} 1$ conditions) when the compaction degree was $96 \%$ and the partial stress was $30 \mathrm{kPa}$. Figure 5 shows the plastic deformation curve of soil samples with different moisture contents (A2, B2, and C2 conditions) when the compaction degree was $96 \%$ and the partial stress was $45 \mathrm{kPa}$. 


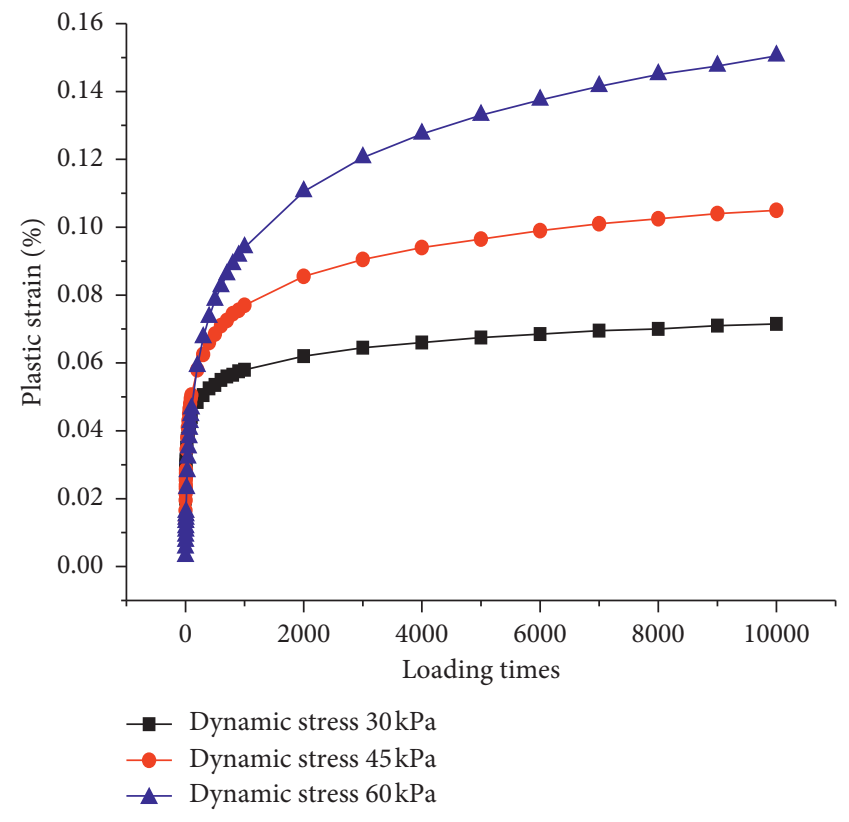

Figure 2: Effect of dynamic stress on plastic deformation (6.8\%).

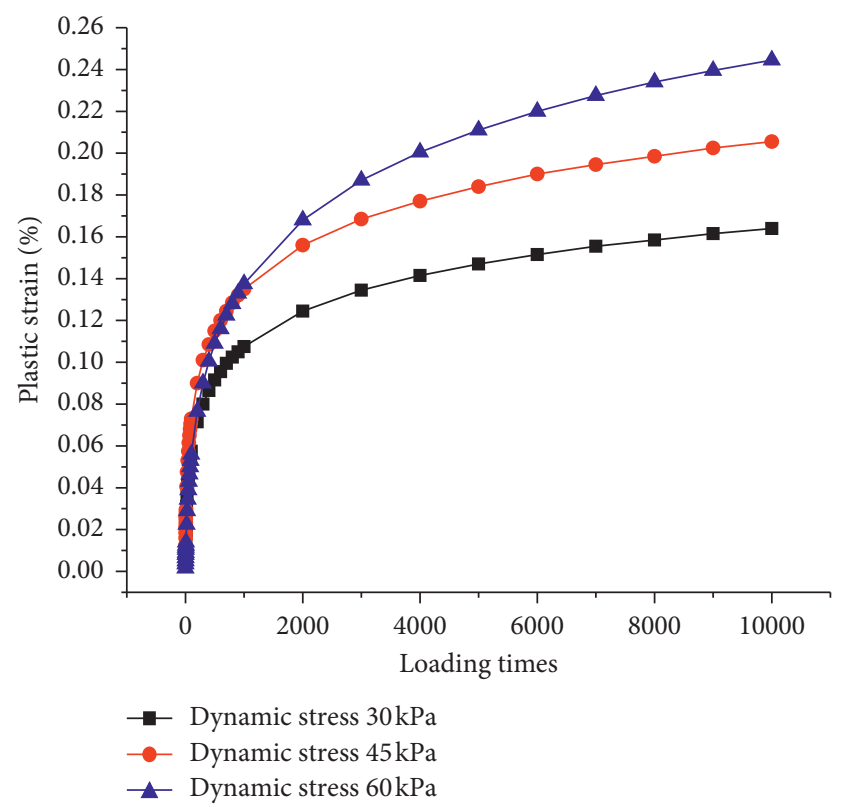

Figure 3: Effect of dynamic stress on plastic deformation (9.5\%).

Figures 5 and 6 show that the plastic deformation of the six groups increased with the increase in the number of loads, and the change trend was basically the same. The plastic deformation substantially increased with the increase in the moisture content of the specimen. When the partial stress was $30 \mathrm{kPa}$ and the moisture content was $6.8 \%$, the plastic strain of 10,000 samples was $0.07 \%$. When the moisture content increased to $8.1 \%$ and $9.5 \%$, the plastic strain increased to $0.13 \%$ and $0.16 \%$, respectively. When the deviatoric stress was $45 \mathrm{kPa}$, the increase in the moisture content also led to a significant increase in the plastic deformation. The test results showed that the effect of the moisture content on the plastic deformation of

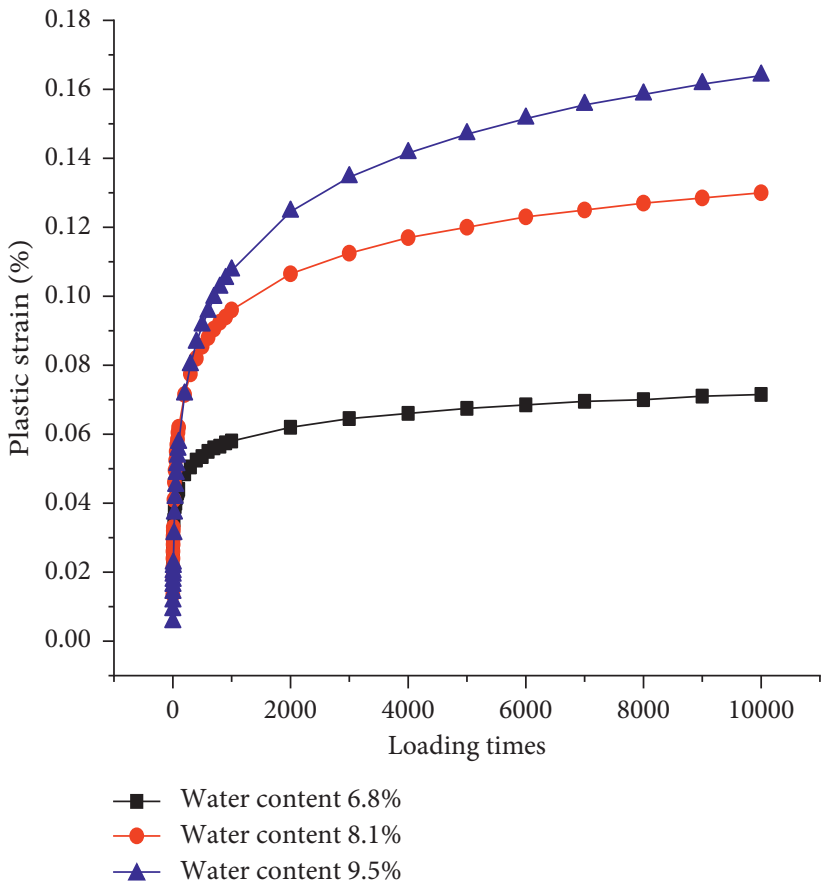

FIGURE 4: Effect of the moisture content on plastic deformation $(30 \mathrm{kPa})$.

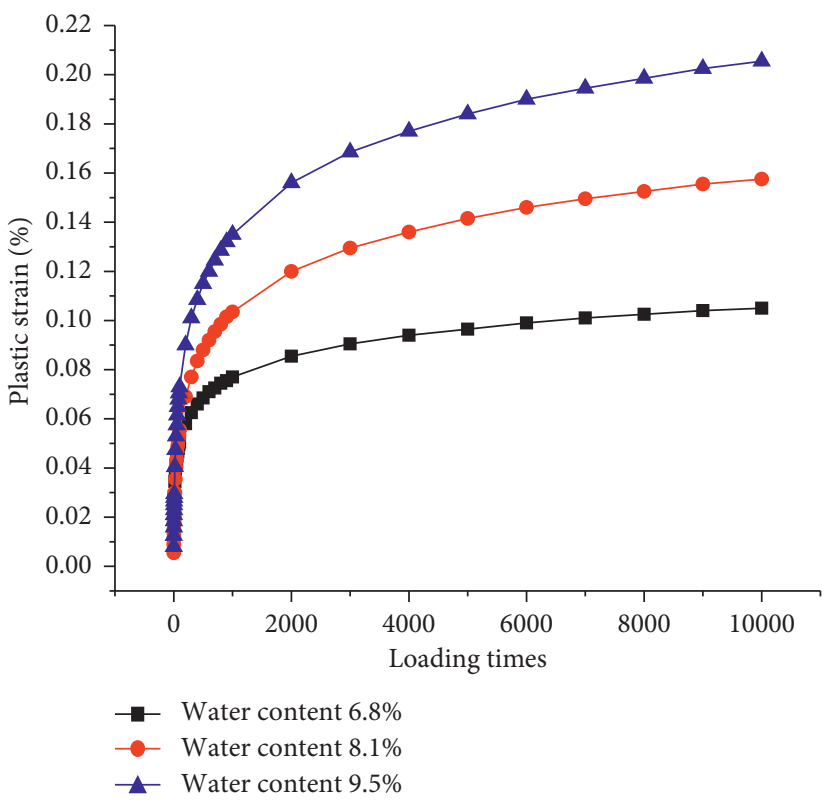

FIGURE 5: Effect of the moisture content on plastic deformation $(45 \mathrm{kPa})$.

subgrade soil was substantial. This is because when the water content of roadbed soil increased, the effective stress of the soil decreased, the pore water pressure increased, and the loadbearing capacity of the soil reduced; thus, the plastic deformation of the subgrade soil increased.

The vehicle load on the conditions of subgrade and soil under different wet and dry conditions varied greatly; waterproofing and drainage measures should be performed well. 


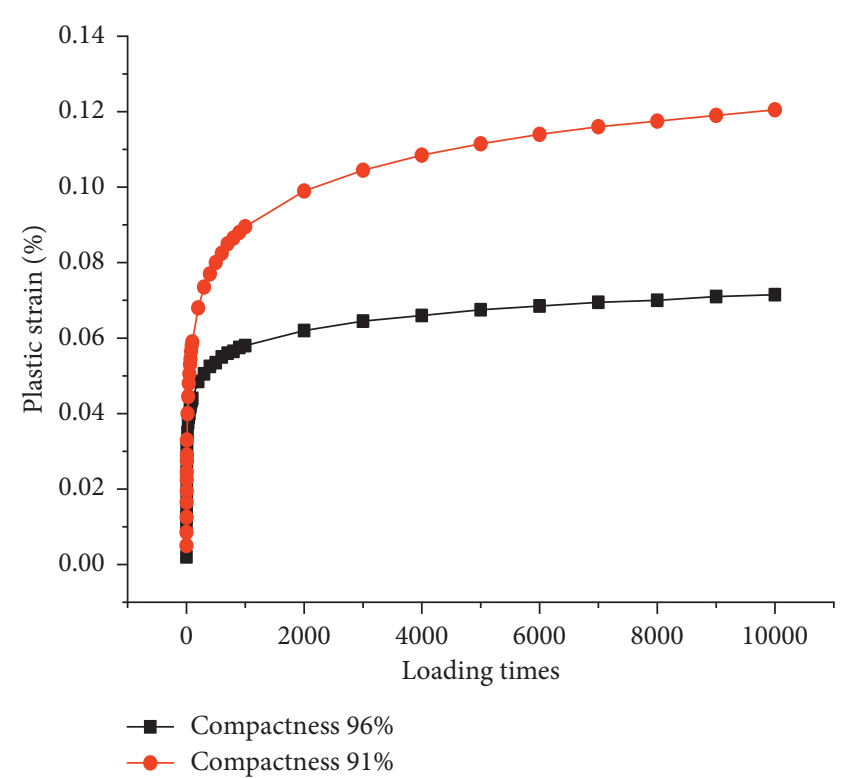

FIgURE 6: Effect of the degree of compaction on plastic deformation $(30 \mathrm{kPa})$.

3.3. Influence of Compaction on Plastic Deformation. Considering the effect of the compaction degree on plastic deformation, the plastic deformation values of soil samples with the same moisture content and partial stress were compared. Figure 6 shows the plastic deformation curve (A1, D1) of different compacted soil samples with a moisture content of $6.8 \%$ and a partial stress of $30 \mathrm{kPa}$. Figure 7 shows the plastic deformation curve (A2, D2) of different compacted soil samples with a moisture content of $6.8 \%$ and a partial stress of $45 \mathrm{kPa}$.

Figures 6 and 7 show the cumulative plastic deformation curves of coarse-grained soils with different compaction degrees. The plastic strain decreases with an increasing compaction degree, with the consideration of the effects of $91 \%$ and $96 \%$ compaction on the plastic deformation. For the soil sample with a dynamic stress of $45 \mathrm{kPa}$ and a compaction degree of $91 \%$, the soil-like plastic strain increased by $50 \%$ compared to that with a compaction degree of $96 \%$ after 10000 cycles of loading; therefore, the compactness had a large influence on plastic deformation. The larger the compactness was, the better the overall performance of the soil was, and the stronger the soil was to resisting external deformation.

\section{Permanent Deformation Prediction Models}

4.1. Model Selection. The prediction model of the permanent deformation of subgrade soil was put forward by many scholars in China and abroad, but there is currently no regression formula between the regression coefficient and the basic physical and mechanical parameters; thus, it does not have certain theoretical significance. The Tseng-Lytton model is currently used in many models. The parameters of the Tseng-Lytton model include resilience strain, moisture content, and dynamic resilience modulus. The other factors can also be obtained by the dynamic rebound modulus, so

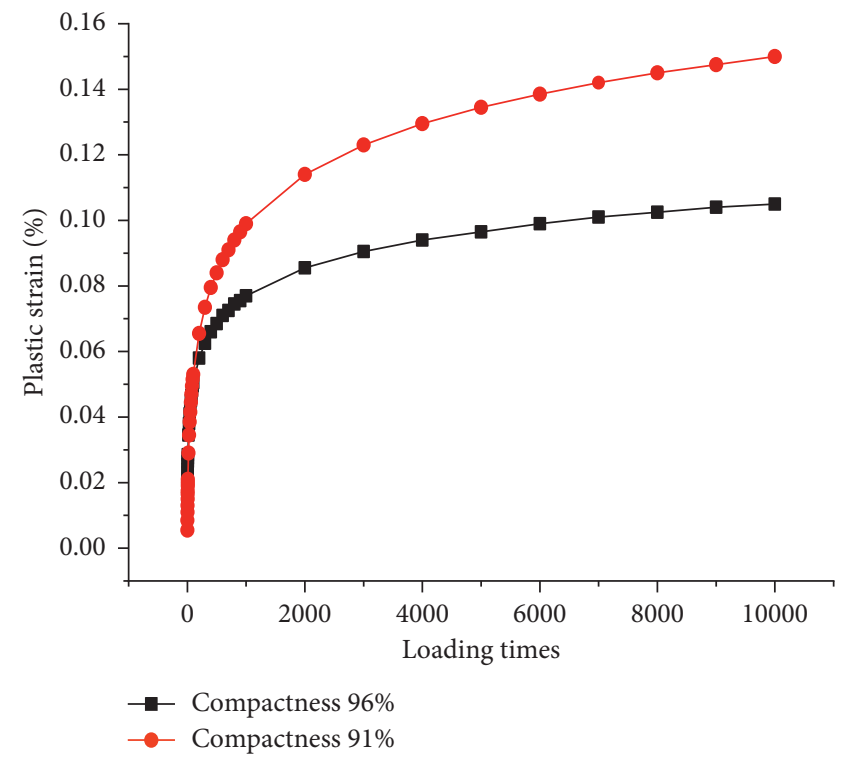

Figure 7: Effect of compaction on plastic deformation (45 kPa).

the parameters involved in this model are comprehensive. Since the Tseng-Lytton model has been validated by a large number of laboratory tests and adopted by the AASHO 2002 design guide, it has high reliability. Therefore, the TsengLytton model was used in this paper to fit the test data. The formula is as follows [15]:

$$
\frac{\varepsilon_{\mathrm{p}}(N)}{\varepsilon_{\mathrm{v}}}=\beta_{\mathrm{r} 1}\left(\frac{\varepsilon_{0}}{\varepsilon_{\mathrm{r}}}\right) e^{-(\rho / N)^{\beta}},
$$

where $\varepsilon_{\mathrm{v}}$ is the vertical strain obtained in the mechanical analysis of the multilayer system; $\varepsilon_{\mathrm{r}}$ is the rebound strain when determining the material parameters; $\beta_{\mathrm{r} 1}$ is the correction coefficient, which is $1 ; N$ is the loading times; and $\varepsilon_{0}$, $\beta$, and $\rho$ are the regression parameters.

4.2. Data Fitting. The least squares method was used to fit the experimental data according to formula (1). The parameters to be fitted are shown in Table 4. The curve fitting correlation coefficient showed that the fitting curve was consistent with the experimental results.

In the multivariate linear regression, the rebound strain parameter was introduced, and the rebound strain had a certain proportional relation with the partial stress, and it was also related to the body stress and compaction degree. To facilitate the application of engineering, the modulus of elasticity and moisture content, which reflected the characteristics of the soil in the model, were used as regression parameters. According to the test, the stress-strain hysteresis curves of different loading times were obtained, indicating that the number of repeated loads had little effect on the rebound modulus. Therefore, the elastic modulus was calculated by using the stress-strain hysteresis curve when the load was applied 100 times. The logarithmic relationships among the moisture content, modulus of 
TABLE 4: Fitting data of the permanent deformation curves.

\begin{tabular}{|c|c|c|c|c|c|}
\hline Working conditions & The spring back of strain $\varepsilon_{\mathrm{r}}(\%)$ & $\left(\varepsilon_{0} / \varepsilon_{\mathrm{r}}\right) \varepsilon_{\mathrm{v}}$ & $\rho$ & $\beta$ & $R^{2}$ \\
\hline A1 & 0.0283 & 0.1321 & 95.3454 & 0.10567 & 0.98859 \\
\hline $\mathrm{A} 2$ & 0.0432 & 0.2066 & 543.647 & 0.13487 & 0.94878 \\
\hline A3 & 0.0589 & 0.2723 & 414.753 & 0.18078 & 0.96081 \\
\hline B1 & 0.0343 & 0.2871 & 2104.77 & 0.15474 & 0.95312 \\
\hline B2 & 0.0528 & 0.2799 & 651.29 & 0.17378 & 0.95154 \\
\hline B3 & 0.0726 & 0.4025 & 1131.93 & 0.18135 & 0.94941 \\
\hline $\mathrm{C} 1$ & 0.0393 & 0.3962 & 6113.19 & 0.19941 & 0.92971 \\
\hline $\mathrm{C} 2$ & 0.0606 & 0.4815 & 3587.81 & 0.15923 & 0.97721 \\
\hline $\mathrm{C} 3$ & 0.0835 & 0.6211 & 6323.82 & 0.14873 & 0.92837 \\
\hline D1 & 0.0360 & 0.2427 & 576.75 & 0.12661 & 0.94081 \\
\hline $\mathrm{D} 2$ & 0.0545 & 0.3046 & 1304.27 & 0.17214 & 0.93742 \\
\hline D3 & 0.0737 & 0.3697 & 1021.53 & 0.17957 & 0.96353 \\
\hline
\end{tabular}

resilience, and partial stress were obtained through multiple regressions:

$$
\begin{aligned}
\lg \left(\frac{\varepsilon_{0}}{\varepsilon}\right)= & -0.002746 E_{\mathrm{r}}+0.0571689 W_{\mathrm{c}} \\
& +0.5791846, \quad\left(R^{2}=0.71\right), \\
\lg (\rho)= & -0.024426 E_{\mathrm{r}}+0.1947276 W_{\mathrm{c}} \\
& +3.6384151, \quad\left(R^{2}=0.75\right), \\
\lg (\beta)= & -0.00461 E_{\mathrm{r}}+0.0112417 W_{\mathrm{c}} \\
& -0.49041, \quad\left(R^{2}=0.53\right),
\end{aligned}
$$

where $w_{\mathrm{c}}$ is the water content, and its unit is \%. $E_{\mathrm{r}}$ is the modulus of resilience, and the unit is $\mathrm{MPa} . \sigma_{\mathrm{d}}$ is the partial stress, and its unit is $\mathrm{kPa}$.

The working condition of this test is 12 , and $\alpha=0.05$. According to the principle of mathematical statistics, the critical value of the correlation coefficient was determined to be $R_{\mathrm{a}}=7.07, R_{\mathrm{a}}^{2}=0.5$. The squared correlation coefficient $R^{2}$ among $\lg \left(\varepsilon_{0} / \varepsilon_{\mathrm{r}}\right), \lg (\rho), \lg (\beta)$, and the moisture content and elastic modulus equations obtained by multiple regression is greater than 0.5 . Therefore, the permanent deformation of coarse-grained soil could be calculated using the above formula.

\section{Calculation of the Permanent Deformation of Coarse-Grained Soil Subgrade}

5.1. Calculation Steps. The foregoing model was used to describe the relationship between the plastic deformation of coarse-grained soil samples and the axial stress level, moisture content, compaction degree, rebound modulus, and loading frequency. To reflect the dynamic stress and deformation characteristics of coarse-grained soil under long-term vehicle loading, the layered summation method of the mechanistic-empirical method was used to calculate the dynamic stress deformation of the subgrade surface. The calculation steps are as follows:

(1) A mechanical analysis of the subgrade model was performed to calculate the subgrade working area based on the conditions required for simulation, and the subgrade working area was divided into sublayers according to depth. At a certain depth of the roadbed, the area where the ratio of the vertical stress $\sigma_{\mathrm{z}}$ caused by the vehicle load to the stress $\sigma_{\mathrm{c}}$ generated by the weight of the soil is greater than 0.1 was the range of the vehicle load influence, namely, the subgrade work area.

(2) The mechanical calculation of the roadbed pavement structure was carried out, and the elastic strain of the subgrade under the specified load was obtained.

(3) Each layered elastic strain was substituted into the prediction model of the permanent deformation of the coarse-grained soil, and the cumulative plastic strain of each layer was obtained. This cumulative plastic strain value was multiplied by the layer thickness to obtain the accumulated plastic deformation of the layer.

(4) The cumulative deformation of each layer of soil in the depth range of the roadbed working area was superimposed to obtain the cumulative plastic deformation at the top of the roadbed. The formula is as follows:

$$
\delta_{\mathrm{p}}(N)=\sum_{i=1}^{n} \varepsilon_{\mathrm{p} i}(N) h_{i}
$$

where $\delta_{\mathrm{p}}(N)$ is the total deformation of the subgrade soil when the wheel load acts $N$ times, $\varepsilon_{\mathrm{p} i}(N)$ is the plastic strain of soil layer $i$, and $h_{i}$ is the layer thickness.

5.2. Example of the Permanent Deformation of CoarseGrained Soil Subgrade. The conditions of this article were selected from the K56 + 300-K56 + 350 section of the Nuchen Expressway. Due to frequent rainfall during the rainy season and the serious vehicle overloading phenomenon, the road section was damaged to varying degrees, which had a certain impact on vehicle travel. The schematic diagram of the subgrade and pavement structure of the road section is shown in Figure 8. The calculation parameters of the materials of each layer are shown in Table 5. 


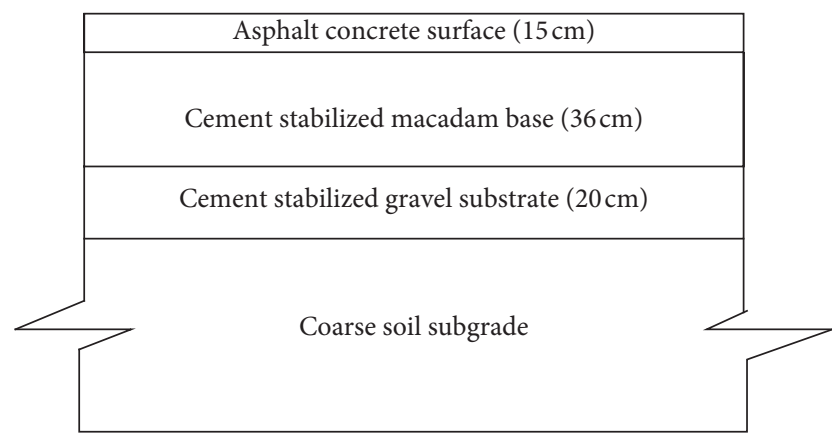

FIGURE 8: Schematic diagram of the subgrade pavement structure.

TABle 5: Calculation parameters of the subgrade pavement materials.

\begin{tabular}{lcc}
\hline Material parameters & Elastic modulus $(\mathrm{Pa})$ & Poisson's ratio \\
\hline Surface layer & $1.4 \times 10^{9}$ & 0.25 \\
Basic layer & $8.0 \times 10^{8}$ & 0.25 \\
Road base & $1.0 \times 10^{8}$ & 0.3 \\
Soil base & $2.0 \times 10^{7}$ & 0.33 \\
\hline
\end{tabular}

Combined with the stratified sum method and the prediction model for the permanent deformation of coarsegrained soil, the dynamic load deformation of the top surface of the coarse-grained soil subgrade under different working conditions was calculated based on $10^{7}$ vehicle load times. The lateral length of the dynamic deformation map of the roadbed had a width of one lane $(3.75 \mathrm{~m})$, and the dynamic load deformation of coarse-grained soil subgrade under different working conditions is shown in Figures 7-9.

5.2.1. Axle Load Size Effect. Comparing the degree of compaction of $96 \%$ and the condition of optimum moisture content, the effects of different axial loads on the cumulative deformation of the roadbed are shown in Figure 9. When the axle load increased from $100 \mathrm{kN}$ to $180 \mathrm{kN}$, the overall deformation of the subgrade surface increased, and the maximum dynamic load deformation increased by 1.2 times from $0.738 \mathrm{~mm}$ to $1.624 \mathrm{~mm}$. The axle load size was one of the main factors of the dynamic deformation of the subgrade.

5.2.2. Subgrade Moisture Content Effect. The dynamic deformation of the subgrade under different moisture content conditions is shown in Figure 10 for a compaction degree of $96 \%$ and an axle load of $100 \mathrm{kN}$. As shown in the figure, when the water content increased from $6.8 \%$ to $9.5 \%$, the maximum dynamic deformation at the top of the subgrade increased from $0.738 \mathrm{~mm}$ to $2.14 \mathrm{~mm}$, which is an increase of 1.9 times.

5.2.3. Compaction Effect. The comparative moisture content was $96 \%$, and the axial load was $100 \mathrm{kN}$. The dynamic deformation of the subgrade under different compaction conditions is shown in Figure 11. The figure shows that when

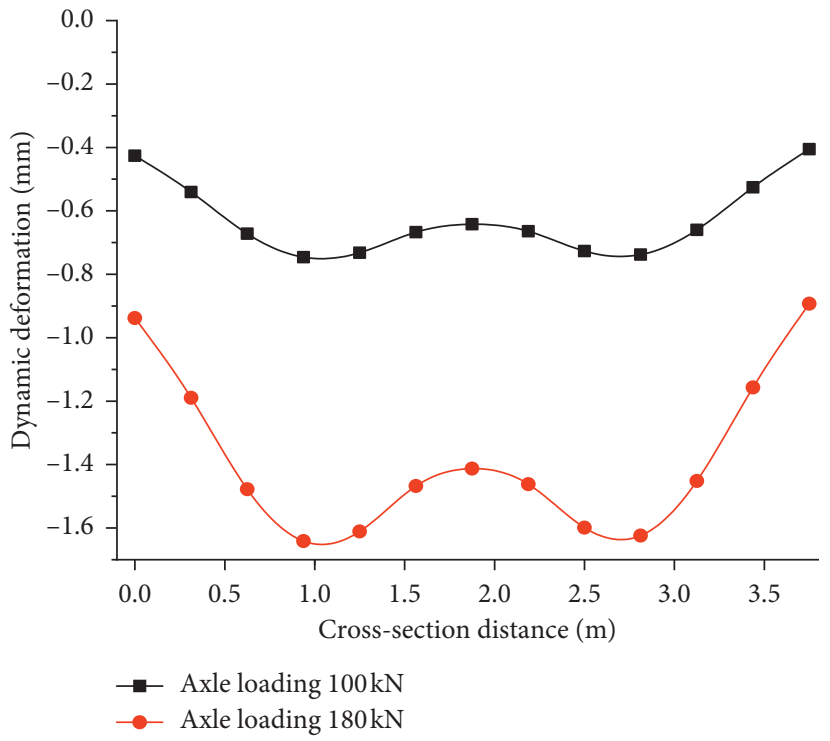

Figure 9: Effect of the axle load on the dynamic deformation of the subgrade.



Figure 10: Effect of the moisture content on the dynamic deformation of the subgrade.

the degree of compaction was reduced from $96 \%$ to $91 \%$, the maximum dynamic load of the subgrade increased from $0.738 \mathrm{~mm}$ to $1.92 \mathrm{~mm}$, which is an increase of 1.6 times.

The deformation of the roadbed was considered under a vehicle load of one lane $(3.75 \mathrm{~m})$ width, as seem in Figures 8-11. The figures show that the dynamic deformation curve is symmetrical and the shape is roughly a "W." The maximum value of the deformation was directly below the wheel, and as the distance from the wheel increased, the amount of deformation decreased. The axial load, subgrade moisture content, and compaction of the vehicle had a large influence on the dynamic deformation of the subgrade. The dynamic deformation of the subgrade 


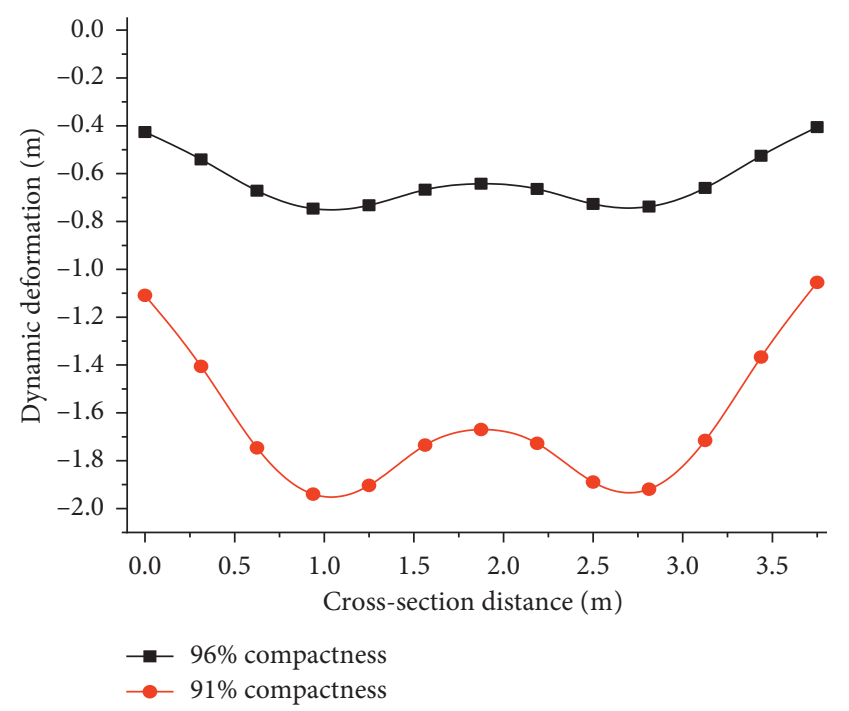

FIGURE 11: Effect of the compaction degree on the dynamic deformation of the subgrade.

increased with the axial load and moisture content and decreased with increasing compaction.

\section{Conclusions}

(1) The analysis of a permanent deformation test shows that as the water content and deviatoric stress increase, the permanent deformation of coarse-grained soil increased, and the permanent deformation of coarse-grained soil decreased with the increase in compaction.

(2) The Tseng-Lytton model was used to fit the data of the permanent deformation test of coarse-grained soil. The fitting results showed that the model can better reflect the deformation law of coarse-grained soil.

(3) The relationships between the logarithm of each coefficient, the moisture content, and the modulus of resilience of the prediction model for the permanent deformation of coarse-grained soils were obtained by multiple regression.

(4) The dynamic deformation laws of the top surface of the subgrade under different axial loading, moisture content, and compaction degree conditions were obtained through the prediction model of the permanent deformation of coarse-grained soil combined with the layered summation method: the dynamic deformation curve is symmetrical and the shape is roughly a "W." The maximum value of the deformation was directly below the wheel, and as the distance from the wheel increased, the amount of deformation decreased.

\section{Data Availability}

The data used to support the findings of this study are available from the corresponding author upon request.

\section{Conflicts of Interest}

The authors declare that there are no conflicts of interest.

\section{Acknowledgments}

This work was financially supported by the National Science Foundation of China (51678073, 51508042, and 51838001) and the Research Foundation of Hunan Province (2016SK2023).

\section{References}

[1] J. H. Zhang, J. H. Peng, J. Li et al., "Characterization of stress and moisture-dependent resilient behaviour for compacted clays in south China," Road Materials and Pavement Design, 2018.

[2] X. Fan, R. Chen, H. Lin et al., "Cracking and Failure in Rock Specimen Containing Combined Flaw and Hole under Uniaxial Compression," Advances in Civil Engineering, vol. 2018, Article ID 9818250, 15 pages.

[3] K. Z. Yan, H. B. Xu, and G. H. Shen, "Novel approach to resilient modulus using routine subgrade soil properties," International Journal of Geomechanics, vol. 14, no. 6, article 04014025, 2014.

[4] Y. X. Huang, Pavement Analysis and Design, China Communication Press, Beijing, China, 1998.

[5] R. P. Elliot and M. R. Thompson, "ILLI-PAVE mechanistic analysis of AASHO road test flexible pavements," Transportation Research Record, vol. 1043, pp. 9-49, TRB, 1985.

[6] H. Lin, W. Xiong, and Q. Yan, "Three-dimensional effect of tensile strength in the standard brazilian test considering contact length," Geotechnical Testing Journal, vol. 39, no. 1, article 20140268, 2016.

[7] H. Wang, H. Lin, and P. Cao, "Correlation of UCS rating with schmidt hammer surface hardness for rock mass classification," Rock Mechanics and Rock Engineering, vol. 50, no. 1, pp. 195-203, 2017.

[8] Y. X. Wang, P. P. Guo, W. X. Ren et al., "Laboratory investigation on strength characteristics of expansive soil treated with jute fiber reinforcement," International Journal of Geomechanics, vol. 17, no. 11, article 04017101, 2017.

[9] Q. G. Guo, Engineering Properties of Coarse Soil and Its Application, Water Resource Publishing House, Beijing, China, 1999.

[10] X. B. Chen, J. S. Zhang, and Z. P. Feng, "Experimental study on rheological engineering properties of coarsely granular red sandstone soil," Chinese Journal of Rock Mechanics and Engineering, vol. 35, no. 3, pp. 601-607, 2007.

[11] D. P. Liu, Study on the Engineering Properties of Aeolian Sand and Gravel Soil Low Embankment under Vehicle Load, Chang'an University, Xi'an, China, 2015.

[12] N. D. Pumphrey Jr. and R. W. Lentz, "Deformation analysis of Florida highway subgrade sand subjected to repeated load triaxial tests," Transportation Research Record, vol. 1089, pp. 49-56, TRB, 1986.

[13] J. H. Zhang, P. Yin, and J. L. Zheng, "Research on critical stress level of Shakedown of red clay in southern hot and humid areas," Journal of Central South University of Technology, vol. 45, no. 4, pp. 1288-1292, 2014.

[14] F. Zhang, Dynamic Response and Permanent Deformation of Subgrand Induced by Heavy Truck in Deep Seasonally Frozen Region, Harbin Institute of Technology, Harbin, China, 2012.

[15] Z. M. He, Z. Y. Xiong, Q. G. Hu, and M. Yang, "Analytical and numerical solutions for shear mechanical behaviors of structural plane," Journal of Central South University, vol. 21, no. 7, pp. 2944-2949, 2014. 


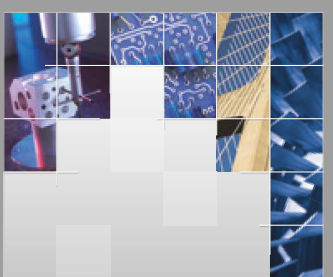

\section{Enfincering}
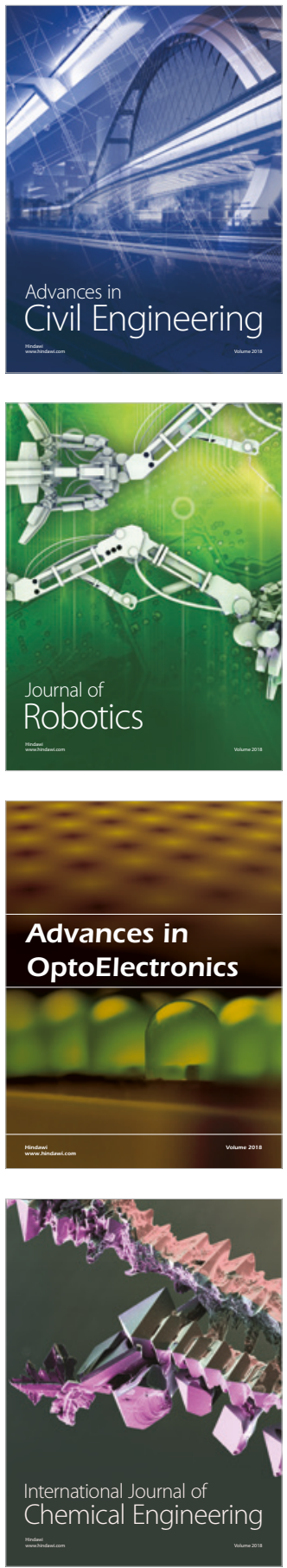

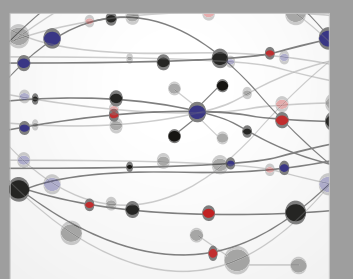

\section{Rotating \\ Machinery}

The Scientific World Journal

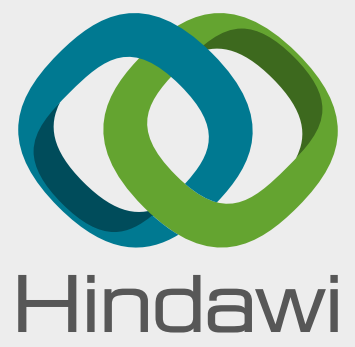

Submit your manuscripts at

www.hindawi.com
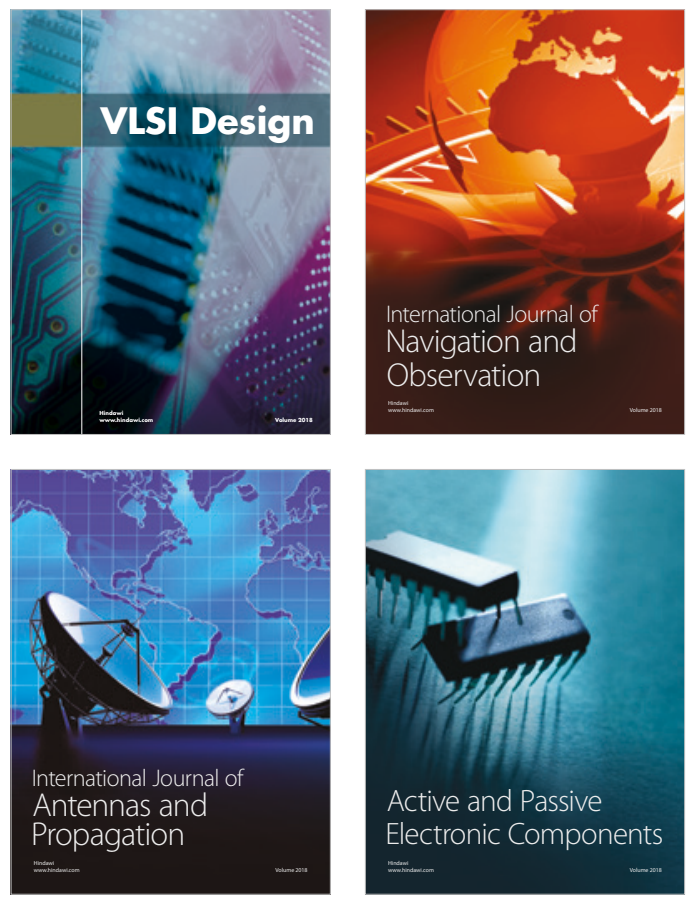
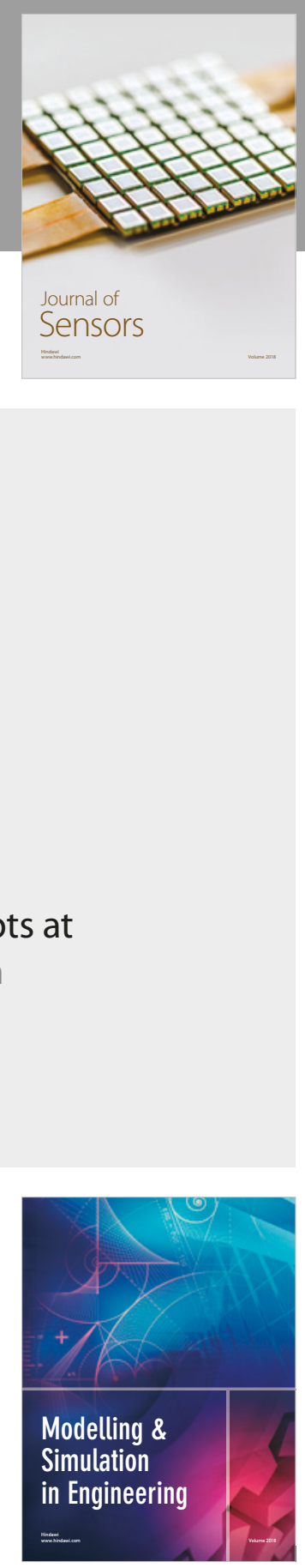

\section{Advances \\ Multimedia}
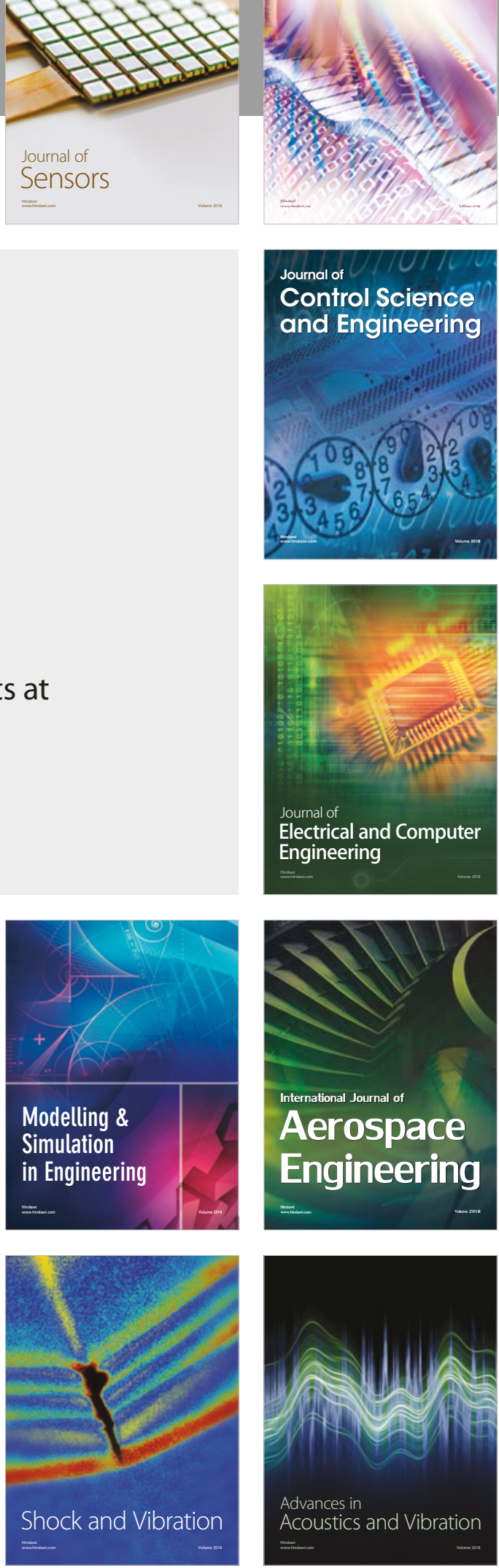